dr hab. inż. Nikolay Lukov

Moskiewski Państwowy Uniwersytet Komunikacji

dr inz. Marek Babet

Politechnika Krakowska

\title{
Przekładnia elektryczna lokomotywy spalinowej prądu zmiennego $z$ asynchronicznymi silnikami trakcyjnymi zwartymi bez falowników trakcyjnych
}

\begin{abstract}
Zastosowanie do napędu na lokomotywach spalinowych trakcyjnych pradnic pradu zmiennego pozwala opracować przektadnie elektryczna pradu zmiennego bez użycia falowników trakcyjnych, zwiększyć wskaźniki techniczno-ekonomiczne tego typu lokomotyw. $W$ artykule przedstawiono opis schematów, wtaściwości $i$ charakterystyk przektadni elektrycznej, w sktad której wchodza - trakcyjna pradnica asynchroniczna i asynchroniczne silniki trakcyjne zwarte.
\end{abstract}

W lokomotywach spalinowych stosowane są przekładnie elektryczne w wariantach: prąd stały; zmienny - stały i zmienny - stały - zmienny. Przekładnie elektryczne w wariancie prąd zmienny - stały i zmienny stały - zmienny posiadają określone zalety $\mathrm{w}$ stosunku do przekładni prądu stałego. Przekładnie elektryczne w wariancie prąd zmienny - stały - zmienny składają się z trakcyjnej prądnicy synchronicznej (TPS) z blokiem wzbudzenia, prostownika trakcyjnego, falownika trakcyjnego (FT) i asynchronicznych silników trakcyjnych (AST) [1-3]. Przekładnie takie opracowano na podstawie układów napędu elektrycznego ze- stawów kołowych elektrycznych pojazdów trakcyjnych, w których nie występują prądnice prądu zmiennego, a energia elektryczna dostarczana jest $z$ sieci trakcyjnej. W przypadku występowania $\mathrm{w}$ napędzie lokomotywy spalinowej trakcyjnej prąnicy prądu zmiennego mogą zostać zbudowane przekładnie elektryczne z zastosowaniem AST zwartych bez wykorzystania FT, które będą charakteryzować się określonymi wymiarami gabarytowymi, masa, ceną oraz wskaźnikami niezawodnościowymi.

W opracowanym projekcie przekładni elektrycznej lokomotywy, w celu zapewnienia płynnej zmiany 
siły pociagowej na obwodzie kół, poszerzenia zakresu prędkości, zwiększenia niezawodności, efektywności oraz poprawy właściwości trakcyjnych lokomotywy, zastosowano trakcyjną prądnicę asynchroniczną (TPA) pierścieniową obcowzbudną [4,5], napędzaną silnikiem spalinowym. Do zacisków TPA podłączone są bezpośrednio AST zwarte, a do jej obwodu wirnika $\mathrm{z}$ pierścieniami podłączona jest przetwornica częstotliwości (PC), która podłączona jest do wzbudnicy synchronicznej (WS) napędzanej silnikiem spalinowym.

Opracowany projekt przekładni elektrycznej prądu zmiennego składa się z następujących elementów (rys.1): TPA 1, której uzwojenie wzbudzenia 2 podłączone jest do PC 3, TPA 1 połączona jest $\mathrm{z}$ wałem silnika spalinowego D 4 i z wałem WS 5, której uzwojenie wzbudzenia podłączone jest do regulatora napięcia (RN) 6 TPA 1, a uzwojenie stojana WS 5 podłączone jest do PC 3, połączonej $\mathrm{z}$ regulatorem częstotliwości (RC) $7 f_{P}$ napięcia TPA 1 . Do uzwojenia stojana TPA 1 podłączone są bezpośrednio AST zwarte 8 , których wały połączone są z osiami zestawów kołowych 9 lokomotywy. Regulatory RN 6 i RC 7 podłączone są do nastawnika maszynisty 10 .

Przekładnia elektryczna działa $\mathrm{w}$ następujący sposób. Stojan TPA posiada typowe uzwojenie trójfazowe prądu zmiennego. Uzwojenie wzbudzenia, rozmieszczone na wirniku, musi posiadać taką samą liczbę par biegunów jak uzwojenie stojana. Wskazanym jest aby uzwojenie wirnika wykonane było jako rozproszone w celu otrzymania sinusoidalnego pola magnetycznego w szczelinie powietrznej TPA. Cechą charakterystyczną TPA jest jej wzbudzenie prądem zmiennym o zmienianej częstotliwości $\omega_{B}$ i zmienna prędkość wirowania wirnika $\omega_{\mathrm{P}}[4,5]$. Ponieważ pole magnetyczne, wytwarzane przez trójfazowy prąd wzbudzenia $\mathrm{w}$ uzwojeniu wirnika, wiruje względem wirnika $\mathrm{z}$ częstotliwością $\omega_{\mathrm{B}}$, to częstotliwość wirowania pola magnetycznego względem uzwojeń stojana $\omega$ równa jest sumie algebraicznej częstotliwości wirowania wirnika $\omega_{\mathrm{P}}$ i pola magnetycznego $\omega_{\mathrm{B}}$, wytwarzanego przez prąd wzbudzenia. W wyniku tego częstotliwość wirowania pola magnetycznego $\omega$ można zmieniać poprzez zmianę $\omega_{\mathrm{P}} \mathrm{i} \omega_{\mathrm{B}}$, tj. można zmieniać jej wartość i kierunek za pomocą PC. Uzwojenie stojana TPA jest uzwojeniem wyjściowym. Niezależnie od stosunku częstotliwości $\omega_{\mathrm{P}} / \omega$ pracuje ono $\mathrm{w}$ trybie prądnicowym. Uzwojenie wzbudzenia (wirnika) TPA jest dla niej wejściowym. Tryb jego pracy zależy od poślizgu pola magnetycznego $S=1-\omega_{\mathrm{P}} / \omega$. Przy ujemnym poślizgu $S\left(w\right.$ zakresie $\omega_{\mathrm{P}}>\omega, \mathrm{S}<0$ ), tj. $\mathrm{w}$ przypadku opóźniania się pola magnetycznego względem wirnika, uzwojenie wirnika wzbudzane jest prądem przy odwrotnym przebiegu faz. Przy tym, uzwojenie wzbudzenia TPA generuje moc aktywną $\mathrm{P}$ (rys. 2, a).

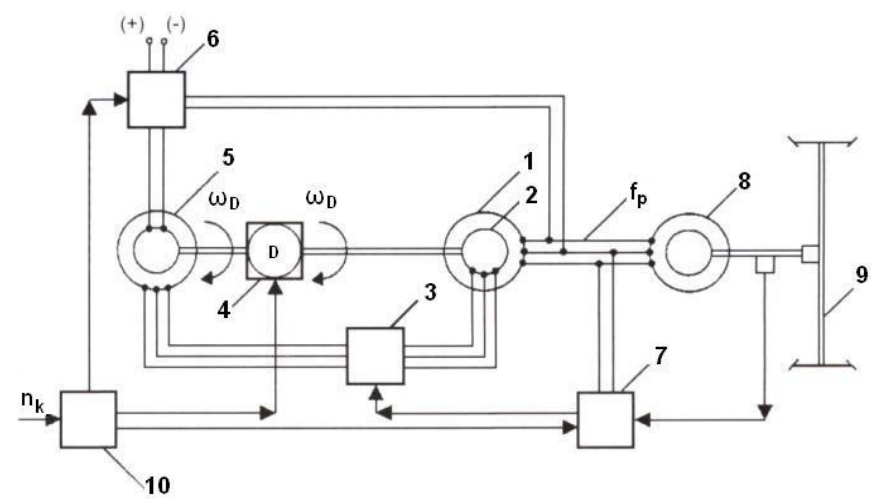

Rys. 1. Schemat blokowy przekładni elektrycznej lokomotywy spalinowej prądu zmiennego z TPA i AST zwartymi bez FT 1 - TPA; 2 - uzwojenie wzbudzenia TPA; 3 - PC; 4 - D; 5 - WS; 6 - RN; 7 - RC; 8 - AST; 9 - osie zestawów kołowych; 10 - nastawnik maszynisty

a)

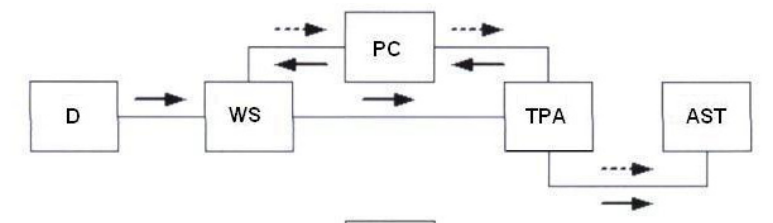

b)

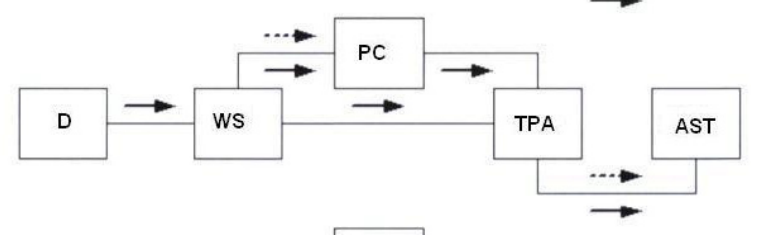

c)

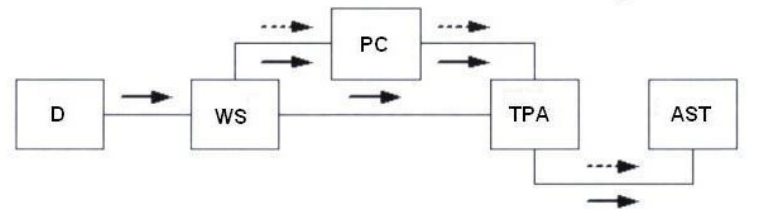

Rys. 2. Schemat blokowy i przepływ mocy aktywnej (-P) i reaktywnej (----- Q) w obwodzie elektrycznym przekładni prądu zmiennego lokomotywy z TPA i AST zwartymi bez FT a) przy poślizgu dodatnim; b) przy poślizgu, równym zero; c) przy poślizgu ujemnym

Poprzez PC ta moc poślizgu przekazywana jest do wzbudnicy WS, która pracuje w trybie silnikowym, tj. moce aktywne $\mathrm{P}$, generowane $\mathrm{w}$ obwodzie uzwojeń stojana i wirnika TPA, powstają w wyniku przekształcenia mocy mechanicznej $\mathrm{P}_{\mathrm{D}}$ silnika spalinowego.

Przy ruszaniu lokomotywy koniecznym jest, aby różnica częstotliwości $\omega$ i $\omega_{\mathrm{B}}$ zapewniła wielkość częstotliwości napięcia TPA $f_{P}=1-2 \mathrm{~Hz}$. Ruszanie lokomotywy realizowane jest poprzez zmniejszenie czestotliwości $\omega_{\mathrm{B}}$ do zera za pomocą PC. Przy częstotliwości $\omega_{\mathrm{B}}=0(\mathrm{~S}=0) \mathrm{w}$ uzwojeniu wzbudzenia TPA przepływa prąd stały (synchroniczny tryb pracy TPA przy $S=0$ ) (rys. 2, b). Przy tym, moc P, doprowadzona do uzwojenia wzbudzenia TPA, jest równa wartości strat elektrycznych w tym uzwojeniu, a moc elektromagnetyczna TPA $P_{\mathrm{EM}}$ wytwarzana jest tylko w wyniku przekształcenia mocy $P_{D}$ silnika spalinowego. Przy częstotliwości $\omega_{\mathrm{B}}=0(\mathrm{~S}=0)$ częstotliwość $f_{P}$ określana jest tylko przez częstotliwość $\omega_{\mathrm{P}}$. 
Dalszy rozruch lokomotywy realizowany jest przy częstotliwości $\omega_{\mathrm{B}}=0$ przez zwiększenie częstotliwości $\omega_{\mathrm{P}}$ od wartości minimalnej do maksymalnej $\omega_{\mathrm{P} \text { NOM }}$

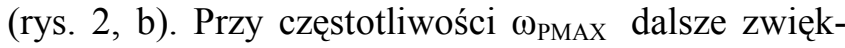
szanie prędkości lokomotywy może być realizowane przez zwiększanie $\omega_{\mathrm{B}}$, jednakże o kierunku przeciwnym, przy czym $\omega=\omega_{\mathrm{P}}+\omega_{\mathrm{B}}$. Przy tym $\mathrm{P}_{\mathrm{AST}}$ lub $\mathrm{P}_{\mathrm{EM}}$ są większe od mocy P uzwojenia wzbudzenia (tj. są większe od mocy poślizgu) (rys. 2, c). Różnica między nimi pokrywana jest z mocy silnika spalinowego $\mathrm{P}_{\mathrm{D}}$. Oznacza to, że moc $\mathrm{P}$, przekazywana na drodze elektromagnetycznej do obwodu uzwojenia stojana TPA, dostarczana jest do TPA od strony wału i od strony uzwojenia wzbudzenia. Źródłem mocy reaktywnej Qp układu (TPA, AST, WS) jest WS, a jej odbiornikami - TPA i AST. Bilans Q podczas pracy TPA i AST $\mathrm{Q}_{\mathrm{WS}}-\left(\mathrm{Q}_{\mathrm{AST}}+\mathrm{Q}_{\mathrm{PC}}\right)=\mathrm{Q}_{\mathrm{TPA}}$. W całym zakresie częstotliwości $\omega$ TPA ma zdolność filtracji, co zapewnia dobry sinusoidalny przebieg napięcia $U_{P}$, wzrost sprawności, niezawodności i zmniejszenie temperatury AST. Regulacja $U_{\mathrm{P}}$ i $\omega_{\mathrm{B}} \mathrm{W}$ zależności od $\mathrm{I}, \omega_{\mathrm{P}}, f_{P}$ oraz obrotów $\mathrm{n}_{\mathrm{AST}}$ AST odbywa się za pomocą RN.

Ponieważ TPA może pracować w trzech trybach (przy ujemnym poślizgu, równym zero lub dodatnim), obszar charakterystyk trakcyjnych lokomotywy podzielony jest linią podziałowa (przy $\mathrm{S}=0$ ) na dwa zakresy. Część charakterystyk w górnym zakresie odpowiada trybowi pracy przekładni przy $\omega=\omega_{\mathrm{P}}-\omega_{\mathrm{B}}$ , a część charakterystyk $\mathrm{w}$ dolnym zakresie - trybowi pracy przekładni przy $\omega=\omega_{\mathrm{P}}+\omega_{\mathrm{B}}$.

Właściwości dynamiczne przekładni elektrycznej odzwierciedla charakter zmian w czasie podstawowych wielkości, określających stan przekładni elektrycznej lokomotywy podczas jazdy pociagu, szczególnie przy ruszaniu i rozpędzaniu się pociągu [6] (rys. 3).
Ustalono, że przekładnia elektryczna przy ruszaniu i zwiększaniu prędkości pociagu pracuje w trybie ujemnego poślizgu pola magnetycznego tylko na krótkim odcinku czasu (120 s, rys. 3). Przy ruszaniu pociagu przy dużym poślizgu wykorzystywana jest bardzo mała moc TPA (o 15-20 razy mniejsza od mocy nominalnej) [7]. Jest to uwarunkowane tym, że w celu ograniczenia maksymalnego prądu rozruchowego TPA i AST przy ruszaniu pociagu, napięcie TPA utrzymywane jest na niskim poziomie poprzez ograniczenie prądu wzbudzenia TPA. W wyniku tego, nawet przy dużym ujemnym poślizgu moc wzbudzenia TPA okazuje się niewielka. Przy tym, wraz ze zwiększaniem mocy TPA i prędkości pociagu (rys. 3, linia 2, 3), częstotliwość wirowania pola magnetycznego prą$\mathrm{du}$ wzbudzenia $\omega_{\mathrm{B}} \mathrm{W}$ początkowym okresie ulega zwiększeniu, a następnie zmniejsza się do zera. Przy częstotliwości $\omega_{\mathrm{P}} \max$ dalsze zwiększanie prędkości lokomotywy może być realizowane przy dodatnim $S$ przez zwiększanie $\omega_{\mathrm{B}}$, jednakże już o kierunku przeciwnym, przy czym $\omega=\omega_{\mathrm{P}}+\omega_{\mathrm{B}}$. Przy tym, co jest szczególnie ważne, zmniejszenie poślizgu pola magnetycznego S (rys. 3, linia 7), pozwala zastosować WS i PC o mniejszej mocy i o mniejszych wskaźnikach masy i wymiarów gabarytowych. W opracowanej przekładni elektrycznej lokomotywy należy zastosować PC $\mathrm{z}$ bezpośrednim połączeniem (bez ogniwa prądu stałego), która nazywana jest przetwornicą ,niskiej" częstotliwości. Do wzbudzenia TPA, która może pracować przy bardzo małej częstotliwości $\omega_{\mathrm{B}}$ względem wirnika, wskazanym jest zastosowanie PC właśnie o „niskiej” częstotliwości, zapewniającej otrzymanie sinusoidalnego prądu wzbudzenia przy pełzających „niskich” częstotliwościach. Jeżeli TPA i WS posiadają jednakową liczbę par biegunów (np. 6), to zastosowanie jako PC prądu wzbudzenia TPA przetwornic o komutacji wymuszonej pozwala realizować

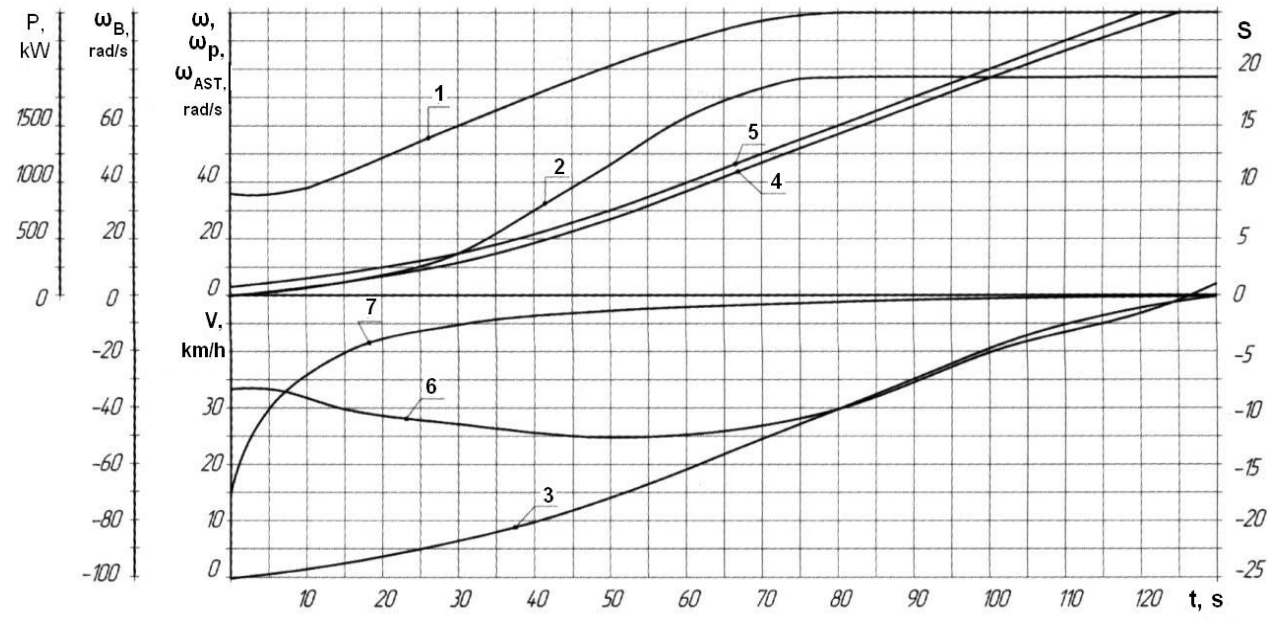

Rys. 3. Charakterystyki zmiany w czasie podstawowych wielkości, określających stan przekładni elektrycznej lokomotywy przy ruszaniu i rozpędzaniu się pociągu, po zmianie nastawnika maszynisty z pozycji 0 na pozycję 15 -ą

1 - częstotliwość wirowania pola magnetycznego wirnika $\omega_{\mathrm{P}} ; 2$ - moc P TPA ; 3- prędkość jazdy pociagu V; 4 - prędkość

kątowa wału $\omega_{\mathrm{AST}}$ AST; 5 - częstotliwość wirowania pola magnetycznego stojana $\omega$ TPA; 6 - częstotliwość wirowania pola magnetycznego prądu wzbudzenia $\omega_{\mathrm{B}} ; 7$ - poślizg pola magnetycznego $\mathrm{S}$ 
najbardziej prosty układ sterowania PC. Charakterystyczną i ważną właściwością takich PC jest zmiana znaku obciążenia reaktywnego Q przy większej częstotliwości komutacji zaworów $\left(\omega_{\mathrm{T}}\right)$, niż częstotliwość przetwarzanego napięcia przez WS $\left(\omega_{\mathrm{WS}}\right)$. Z zasady działania przekładni elektrycznej lokomotywy wynika, że PC dla TPA powinna być wielofazową; przy przejściu przez częstotliwość synchroniczną $\omega_{\mathrm{B}}=0$ $(\mathrm{S}=0)$ przebieg napięcia $\mathrm{w}$ fazach na wyjściu PC musi zmieniać swój znak, dzięki czemu pole magnetyczne zmienia swój kierunek wirowania względem wirnika; przy częstotliwości synchronicznej $\omega_{\mathrm{B}}=0(\mathrm{~S}$ =0) PC musi, w zależności od położenia fazowego wirnika, w odpowiedni sposób rozdzielać prąd stały wzbudzenia pomiędzy fazami uzwojenia wirnika TPA. PC musi być rewersyjną dla mocy aktywnej i reaktywnej; wysoka sprawność musi być zapewniona przez kluczowy tryb pracy przełączanej aparatury półprzewodnikowej. PC nie jest wykonywana na pełną moc AST, a jedynie na wielkość mocy wzbudnicy TPA. W trybie zwarcia przez PC nie przepływa cały prąd zwarcia, co zapewnia bardziej dogodniejsze warunki jej pracy w porównaniu z przekładnią elektryczna, w której przez FT przechodzi pełna moc AST. Masa i wymiary gabarytowe elementów przekładni elektrycznej lokomotywy w znacznym stopniu zależą od mocy wzbudzenia TPA, która równa jest pierwiastkowi kwadratowemu z sumy aktywnej mocy wzbudzenia do kwadratu i mocy reaktywnej wzbudzenia do kwadratu i określa moce WS i PC (rys. 2). Przyjmując, w celu uproszczenia analizy, że straty $\mathrm{w}$ uzwojeniu wzbudzenia TPA nie występują, tj. moc obwodu wzbudzenia równa jest mocy poślizgu $\mathrm{P}_{\mathrm{B}}=$ $\mathrm{S} \cdot \mathrm{P}_{\mathrm{EM}}$, oraz uwzględniając zależność $\mathrm{Q}_{\mathrm{B}}=|\mathrm{S}| \cdot \mathrm{Q}$, można zależność do określenia pełnej mocy obwodu wzbudzenia przedstawić w postaci $\mathrm{S}_{\mathrm{B}}=|\mathrm{S}|$.

gdzie Q - moc reaktywna TPA i AST. Z ostatniej zależności wynika, że moc obwodu wzbudzenia jest tym większa, im większy jest maksymalny poślizg wg wartości bezwzględnej. Stąd wynika wniosek: uwzględniając jako kryterium - zmniejszenie wskaźników masy przekładni elektrycznej, pożądanym, z zakresów roboczych poślizgu, jest ten, przy którym maksymalna moc obwodu wzbudzenia posiada najmniejszą wartość względną. Moc wzbudzenia, masa i wymiary gabarytowe podstawowych elementów przekładni elektrycznej (rys. 2) okazują się największe przy pracy TPA $\mathrm{w}$ zakresie ujemnego poślizgu i najmniejsze - podczas pracy z $\mathrm{S}>0 \mathrm{i}$ z $\mathrm{S}=0$.
We wszystkich przypadkach racjonalny zakres poślizgu $\mathrm{S}$ wybierany jest $\mathrm{z}$ uwzględnieniem mocy, zakresów zmian $\mathrm{n}_{\mathrm{AST}}$ i prędkości, przy których swobodna moc silnika spalinowego w pełni wykorzystywana jest na cele trakcyjne.

Opracowany projekt przekładni elektrycznej posiada znaczące zalety w stosunku do znanych przekładni prądu zmiennego. Zapewnia ona płynną i ciągłą zmianę siły pociaggowej na obwodzie kól, a także zmianę prędkość lokomotywy bez stosowania FT. Przekładnia ta cechuje się dużą niezawodnością, mniejszą cena, wyższą sprawnością, niż znane przekładnie elektryczne lokomotyw.

\section{BIBLIOGRAFIA}

1. Луков Н. М. Передачи мощуности тепловозов: учеб. для вузов ж.-д. трансп.; под ред. Н. М. Лукова. Москва. Транспорт, 1987. 279 с.

2. Струнге Б. Н. Регулирование частоты вращения и мощности дизель - генераторов тепловозов. Москва. Транспорт, 1976. 112 c.

3. Быков В. Г. Пассажирский тепловоз ТЭП70. Москва. Транспорт, 1976. 232 c.

4. Алюиіин Г. Н. Асинхронные генераторы повышенной частоты. Основы теории $и$ проектирования. Москва. Машиностроение, 1974. $352 \mathrm{c}$.

5. Торопиев Н. Д. Асинхронные генераторы автономных систем. Москва. Знак, 1998. 288 с.

6. Луков H. M. Автоматические системы управления локомотивов: учеб. для вузов ж.-д. трансп. Москва. ГОУ «Учебно ᄀметодический центр по образованию на железнодорожном транспорте», 2007. $429 \mathrm{c}$.

7. Винокуров B. A. Электрические машины железнодорожного транспорта. Москва. Транспорт, $1986.511 \mathrm{c}$. 